Boise State University ScholarWorks

Materials Science and Engineering Faculty

Publications and Presentations

Department of Materials Science and Engineering

6-23-2018

Valuing Women's Contributions: Team Projects and Collaborative Writing

Jennifer C. Mallette

Boise State University

Harold Ackler

Boise State University 


\section{Valuing Women's Contributions: Team Projects and Collaborative Writing}

\section{Dr. Jennifer C Mallette, Boise State University}

An Assistant Professor of English at Boise State University, Dr. Jenn Mallette teaches technical communication at the undergraduate and graduate level. In addition to working with STEM students in her undergraduate technical communication course, she collaborates with faculty in the College of Engineering to focus on enhancing writing education in engineering courses. Her other research focuses on women in engineering, and she has recently published on the results of a case study exploring the connections among women's experiences in engineering, their identities as writers, and their writing.

\section{Harold Ackler, Boise State University}




\title{
Valuing Women's Contributions: Team Projects and Collaborative Writing
}

\begin{abstract}
Team projects offer opportunities for student engineers to learn how to work on a team and produce collaborative written reports. However, research has shown that women often do more writing during these projects, and that their writing labor is unrecognized or undervalued, particularly when the technical work is viewed as more essential. In this paper, we examine the results of a study focused on the writing component in a year-long senior capstone materials science and engineering (MSE) course sequence. This course requires students to complete projects for clients and produce a written report, among other deliverables. To focus more on writing education, the engineering professors brought in an English professor, who researches engineering communication and is coordinating this project, to consult on assignments, comment on student work, and present on writing topics, including managing the writing aspect of collaborative work. Here, we assess the impacts of interventions on student writing and collaboration, focusing on women's experiences through a series of interviews. These interviews focused on learning more about women's past experiences working on teams and the effects of the course interventions. Particular to women's experiences, we argue that by making the writing labor more visible in the project and insisting that each student contribute to the writing, women's contributions will not only be clearer but also more explicitly valued and their experiences will be more positive overall. After describing the findings, we offer recommendations to continue improving women's experiences in project-based classroom settings. These recommendations focus on ways engineering instructors who assign writing can ensure women's contributions are both visible and valued in evaluation.
\end{abstract}

\section{Introduction}

A hallmark of engineering courses, regardless of discipline, is team projects. Team projects offer opportunities for student engineers to approximate engineering work environments, where collaboration is not only typical but necessary, producing written reports that communicate the results of their projects [1]. These projects are often sponsored by an industry partner, providing students an audience outside of a school setting and a chance to contribute to solving a realworld problem that can prepare them for the workplace [2, 3]. Ideally, team projects allow students to develop skills that will be transferable to a workplace setting, where individuals must work and write with others within an organization $[1,4]$.

These projects, however, may present challenges for women and other underrepresented students. For one, students are frequently asked to collaborate without clear guidance or structure, a practice that "impedes students' ability to learn the professional communication practices of their disciplines" [1]. In addition, interpersonal communication and conflict is a significant component of successful group projects, and those who are seen as outsidersparticularly women - may communicate in different ways than expected by their peers and their discourse community $[1,5]$. Finally, successful collaborative work requires individual students 
to cede control over the final project, which may be a challenge for achievement-oriented students; successful collaboration requires strong communication and trust in other members [1].

While some scholars theorize that collaborative learning offers space for women to engage socially, evidence suggests that women are more likely to have negative experiences with group work [5]. Negative experiences in team settings may cause women to feel less valued, different, and or emphasize the fact that they don't belong, all factors that can lead to women leaving engineering [5]. Furthermore, women often "report feeling that they must work harder than their male peer to get teams to acknowledge the work they've done" [5]. In fact, men tend to underestimate their women peers' competence and knowledge in the classroom [6] and are likely to dismiss what they view as female-typical speech acts [5]. Other research suggests that in college courses, writing specifically is undervalued or invisible when compared to more technical or computer-based work, work frequently controlled by men [7]. In addition, women do more writing, which, while essential to engineering practice, is often undervalued or not as visible as technical design work $[8,9]$. These labor divisions, where women are likely to be doing the work of science but not receiving credit for it, persists in engineering and other science disciplines and offers one explanation of gender gaps in publication and grant funding [10].

On the other hand, project-based courses also present opportunities for women and other underrepresented students. For one, women are more likely to view themselves and be viewed by their peers and instructors as stronger communicators [11, 12, 13]. For some women, writing ability provides tools to demonstrate competence in school and workplace settings [9]. In other settings, hands-on, project-based experiences in engineering courses may enable students to identify more fully as engineers, increasing retention [14]. So while project-based courses with required collaboration can pose problems for women, these courses also offer the potential to increase representation of women and other underrepresented groups if structured deliberately.

This paper examines preliminary explorations of approaches that could improve the experience of women in engineering collaborative projects, specifically in materials science and engineering (MSE). Focusing on two women's experiences, we examine the potential benefits for women of more purposefully integrating writing into engineering project courses and structuring the collaboration in a way that acknowledges writing. In addition, these strategies may improve all students' experiences in project courses because it provides structure to collaboration, supports developing skills in working and writing in teams, and acknowledges the writing produced and each writer's specific roles.

\section{Context: Engineering-English Partnership}

The senior capstone experience in MSE at Boise State University is a year-long course sequence during which student teams work on projects sponsored by paying clients outside the university. Sponsors are typically companies but may also include national laboratories, nonprofit organizations, and municipalities such as water districts. In addition to their project experience, the students acquire an array of nontechnical skills, with oral and written communication being most emphasized. Students develop skills writing documents ranging from a concise cover letter 
to deep, comprehensive collaborative project reports for their sponsors. The course itself is taught by two materials science faculty members, including one (Harold Ackler) with industry experience that informs the course approaches.

Prior to the senior capstone, students have been introduced to these areas of focus in their junior year. The junior lab experience is a year-long sequence of advanced, project-based courses in which students must write updates and final reports, proposals, and present their work. Projects are one to five week long, in-depth modules in which student teams investigate the processing and characterization of materials and also design, fabricate, and test simple parts using the materials under study. In the fall and spring courses, the last three to four weeks of the semester are allocated to student-initiated projects for which teams submit brief proposals to conduct the work. After instructor approval, the teams conduct the work, present periodic project status updates, and present their projects to the class at the end of the semester. These courses provide the foundation for both written and technical work in the senior year.

Because writing is essential to success in these junior and senior-level courses, the MSE program has been exploring approaches to ensure their students are able to write effectively in their coursework as well as graduate prepared to write for the workplace. At the end of 2016, Janet Callahan, the department chair and one of the senior project course instructors, contacted Jennifer Mallette (referred to as Jenn throughout), an English professor, to discuss the possibility of having Jenn speak to the materials science senior-level project course in Spring 2017. Jenn, who teaches both undergraduate and graduate courses in technical writing and researches engineering communication, visited the course four different times that semester, discussing a range of topics related to report writing, technical style, and communicating clearly in the sciences. While useful to the students, Jenn, Janet, and Harold all recognized that the impact of these visits was limited; ideally, the English professor should be more integrated and involved.

To increase the impact of writing instruction in the course, for the next academic year (20172018), Jenn was embedded within both the junior and senior-level project courses. Working closely with the two project course professors, Jenn contributed to course planning, led specific course sessions on writing and communication, and provided formative and summative feedback on student work. After receiving feedback on her involvement, Jenn, Janet, and Harold made adjustments to Jenn's role in the second semester, providing more time for Jenn to work one-onone with students and their writing. To assess the impacts of the integration of writing instruction, Harold and Jenn decided to collect data to examine if the writing improved, how the students were using specific elements of the writing instruction, and finally, what affect the methods had on the experiences of women in the class. The latter is the focus of this paper.

\section{Methods}

To assess the impact of the course approaches on student writing, Jenn and Harold set out to collect data on student performance and attitudes toward writing. Approved by the university's Institutional Review Board, data collection included surveys of students, writing samples, and inperson interviews. End-of-semester course evaluations provided another form of data collection. 
On the evaluations, Harold added questions specifically about the writing component of the courses to get another glimpse into student perspectives.

The goal of these methods was to collect a range of information from students to assess the impacts the collaboration had on their writing development and to understand how students perceived Jenn's involvement as part of a larger project examining methods for teaching writing. At this time, data collection is still in process, and we intend to extend the study to next year to collect data on the juniors who will be seniors. This paper is reporting on research in progress. Because of the delays in getting IRB approval and the challenges in recruiting participants and obtaining survey data, we intend to refine the study, using the preliminary findings reported on here to improve and expand the approaches to collect more substantial data and to triangulate.

In this paper, we focus on the findings from two sets of semi-structured interviews from the senior project course: a preliminary interview that asked background questions about each participant's experiences with collaborative work and writing (see Appendix A for specific questions), and a final interview that focused on the collaboration in the senior project course (see Appendix B for specific questions). A second round of interviews will be completed at the end of the Spring 2018 semester. While seven students initially signed up to participate, two students, both women, completed both interviews. Both women are traditionally-aged college students who are white and cisgendered.

While more quantitative data can provide essential big picture data, qualitative case studies have the advantage of highlighting specific experiences, focusing on the particular instead of the general [15]. In other words, case studies provide rich context and detail, though researchers must be careful about generalizing what they find. In addition, assessing women's experiences more quantitatively may not be possible because of the number of women present in a given engineering program (the MSE program studied here has only 6 women out of a cohort of 22 enrolled in the senior project course) and because their grades or other methods of numerical evaluation may not adequately reflect their experiences. This paper focuses primarily on these two cases, though future work will expand the methods to collect other forms of qualitative and quantitative data to triangulate the findings and provide more generalizable data.

For this study, each interview was recorded. The recordings were then transcribed using a transcription service. After receiving the transcripts, Jenn reviewed the transcripts to identify themes and key ideas. The quotations included here have been edited lightly to improve readability. Where bracketed ellipses $([\ldots])$ are used, the original quotation has some text removed. Regular ellipses (...) indicate pauses by the speaker in the original conversation.

Finally, member checks were conducted with the participants: each individual was offered the chance to review the final document to clarify quotes, summaries, or analyses for accuracy. This final step ensures that each participant's original intentions and meanings are accounted for and that over-interpretation or misrepresentation did not occur. Both participants reviewed this paper and indicated that what was written conveyed their intended meaning. 


\section{Findings}

The two students who agreed to participate in the interview phase were both traditionally-aged women, Michaela and Sally. Since both of the students were seniors, they had completed courses in their major, most of which involved collaboration in various ways. Both talked about the spring semester of their junior year, where they had collaborative projects (with written components attached) in every class they took. While this paper focuses on only two participants, their stories point to potential interventions that can improve women's experiences that we plan to expand and evaluate.

\section{Previous project experience}

In the preliminary interview, both participants were asked to provide details about three or so past experiences in collaboration. While Sally's experiences seemed mostly positive, Michaela had one project that was, as she said, "by far the worst collaborative project I've ever had before." In this project, Michaela was teamed up with three men, one of whom was from a major outside materials science. She was not allowed to choose her group, and the leader was assigned rather than selected by the group, though no other roles were outlined or assigned. Michaela was assigned the leader for this group, a role she neither wanted nor was accepted by the other members of the team. As Michaela described the project, "So I was chosen to be the leader, like forced to be the leader. I was also the only girl in my group. That was definitely the most stressed I've ever been...My group like repeatedly did not show up to meetings, did not respond to emails, text messages. Yeah, it was bad." For her, the issues stemmed from the composition of the group - one member stopped participating and the other two refused to listen to ideas even from the instructor - and the fact that roles were assigned for them. As the only woman on the team, Michaela was conscious that gender may have also played some role: "I don't know if it was because of gender or because I'm kind of soft spoken, but I definitely was not seen as an authority figure whatsoever."

Michaela ended up doing the vast majority of the work, with the other participants contributing little or nothing to that project. The project was to build a mechanical testing machine, and the written products involved a report that provided details about the machine and a justification of design choices as well as a video. She explained, "For that project, I definitely did a minimum of $95 \%$ of the writing. I also wrote the outline for the video and had to force one of the other students to record his voice reading exactly what I wrote for the video just so he could say that he did something for the project." As she talked about it, it was clear that the experience was frustrating, as she made sure to emphasize: "I'm so bitter about that project." Thus, what Michaela might have learned from the project was overshadowed by her negative experiences working collaboratively.

However, this experience was the only one that Michaela found problematic, and, like Sally, she spoke positively about her other experiences. Michaela detailed another project that occurred the same semester, where she was able to choose her team and where the division of labor was much more even. As she explains: 
I guess because we were able to choose our group, we chose people that we know fairly well. We all already kind of knew each other's strengths, so we decided based off of that. We just kind of fell into our roles. We all knew what we were good at and what everyone had time for and were comfortable with. From that, we chose our roles from there.

For Michaela, that project's success was related to choice, both in roles and teammates, as well as knowing teammates and their strengths and being able to work to one's strength. Michaela also felt that the writing was split evenly among all members, rather than having one or two take on the majority of that work, and she was able to work in the area she felt strongest in, which was data analysis.

In addition to working with classmates she got along with and who contributed equally, this team was composed entirely of women. Although the team's composition of all women was unintentional, Michaela believed that gender may have also played a role in making the collaboration easier. She points out, "There definitely could be a little bit, based on gender, for it being easier. But I can also think of a lot of guys in my class that would have worked equally well. There's always a small group of guys that most of the women don't want to work with." She is conscious that while most of her classmates make good teammates, most of the women have a few male students they would rather not work with.

The other past collaborative writing experience Michaela has had involves an aerospace student organization. In that group, she is currently the president, which means she is responsible for grant proposals and event planning. One trend she noted was while the group's membership was mostly men, "most of the leaders have been the women in the group." In fact, the group has three or four women participating out of a membership of $15-20$, yet " $50 \%$ of the leadership has been women." She later expressed that this connection may have to do with the fact that women have often been in leadership roles since the founding of the group - in fact, she became the president because the past president (also a woman) encouraged her to pursue it. She remarked, "I have no evidence to base this off of, but it could potentially be one of the reasons that some of the men don't want to be in the leadership roles because it's at least half led by women. I don't know if that would have an affect or not, but it definitely seems like most of the guys just hang back."

She also pointed out that "a lot of the members prefer being, not hands off, but they don't want to commit to a leadership position, and so it's really hard getting someone's time to revise it [grant writing] and look over [the grants]." She finds that she ends up sending proposals to a few of the leaders and members who are strong writers. Generally, these grant proposals have been successful in that the organization has received funding for projects, but at times she struggled to recruit members to contribute to the writing production.

Sally also focused on several collaborative experiences from her junior year and one experience working as an intern. In these group projects, she did not have a leadership role. Her role, however, focused on the writing: "So I definitely did a lot of the writing for a lot of the groups 
and kind of aggregation of data, so I would be the one that would assemble everything once everything was collected." Each project had writing associated with it, whether it was a more formal report/written document or a presentation (or both).

One example she provided was for the communications-in-the-discipline (CID) designated course, which requires substantial writing. Sally noted that they ended up producing more writing than was used in the final report, though the final product was approximately 10 pages. She explained that "you had to do the annotated bibliography and you had to summarize different articles and you had to ... basically each step was done so that in the end you theoretically just had to put everything together to make your final report." The class also required a presentation that summarized the key ideas in the report. In terms of division of labor, "they pretty much split the writing four ways, so everyone did the exact same writing, it was just a different focus" She pointed out, however, that "the final report was definitely disjointed because I don't think we really edited it," which highlighted one of the primary issues instructors encounter when reading and evaluating collaboratively written documents.

The other example from school that Sally provided was the same project that was disastrous for Michaela. However, Sally found the experience more successful. In this project, the labor was divided based on skill and ability: one teammate knew how to weld and so could build the device they were designing, so the other two (including Sally) conducted research. Sally ended up doing the majority of the writing as her contribution, and thus the final product was much more cohesive. She also explained that their project received a high grade because of the quality of the machine they built rather than the quality of the report; for that project, she felt that "the writing definitely wasn't emphasized," and the effect of writing on the overall grade was unclear.

Both women were asked to rate their writing skills in connection with their own assessment as well as a comparison to their peers. Michaela rated her writing skills as not "particularly good [...] pretty average;" however, she mentioned her "technical writing is at least on par with where it should be for grad school or industry." In addition, she has been able to observe how her writing skill has developed and gotten stronger over time from class to class and project to project.

Sally, however, rated her own skills as strong, arguing "I'm definitely in the top ten percent of people I've encountered" and that she was efficient in writing as "definitely a fast writer." As she remarks, "If I know what I'm talking about, if I have a clear picture, I can write things in a very short amount of time, so it's always been really easy for me to write what I'm trying to write." So for Sally, writing is easy, and it's easy for her to do it quickly and efficiently, so she often takes on the writing roles on collaborative projects. In fact, she knew that being good at writing meant she was asked to (or actively took on) the writing portions of assignments: "See, I think they were like, oh, you're going to write, that's great, just do that. That's the response I've gotten from a lot of engineers in my classes, just like okay, you can write this because you write well." Her skills in writing led her to assert that "I definitely market myself as a less technical engineer" and instead as someone who could take on "management positions or something in between 
engineering and marketing." She emphasized, however, that this was a choice she made, to not develop her technical skills as much as she could because "I've always been interested in communication more so than the actual technical side because a lot of times it [the technical side] just bores me." She attributed her skill to her interest in writing and her experience writing as first a homeschooled student and later as a high school student taking creative writing electives.

One series of questions focused on gender and its connection to writing skills. In terms of influences of gender, Michaela argued that based on her experiences working in collaborative settings, the women were stronger writers, a belief echoed elsewhere [12, 13]. She said:

I tend to think that the women in materials science are better writers than the men. I have no idea why, like why that might be. But they tend to write...I think the men and women equally understand the technical, like what needs to go in where. But I think the women that I've worked with so far are better at articulating it in a way that, I don't know, a way that flows better, I guess.

She also pointed out that while "There's a lot of the men that write pretty well also," she believed that the men's writing "needs more editing, like more sentence structuring and stuff like that."

Sally also believed that women possessed stronger writing skills. She claims "I do think that women have an easier time to put things into words and so that could be based on gender, just me writing, just because I think I found that it's easier for a lot of women to write." Sally was particularly careful not to attribute all differences to gender, including how tasks were broken down. She felt task breakdowns along gender lines were more related to skills and opportunity to develop both technical and writing skills. However, she did seem to believe that those opportunities were related to gender-based differences in brain development: "So I think the guys are at a disadvantage that way because their brains just like can't interpret the information at that age and then when they are finally, like, grown up enough to understand those things, they've already lost the opportunity." She also pointed out that in her experience, the men are less stellar writers:

I don't think I've worked with enough of my classmates to say that for sure, but I would say that ... so like in our senior class there's pretty much this one guy and this one girl, they're like the top grades and they work really hard and they know everything, things like that, and so I would say that I have worked with that guy in a group and his writing was like average, I'd say. I haven't worked with the girl but I would probably assume that she's a good writer because she researches and she does a lot of publications and stuff.

However, she is also careful to note that this assumption is based on limited information. 
Overall, both women generally had positive experiences around collaboration, and they felt that the materials science program emphasized writing and communication in ways that were beneficial, particularly when compared to other programs. Sally pointed out that "I was actually expecting to be like miles above my classmates but since we have been focusing on writing a lot I would say that they're actually way better than I expected my fellow engineers to be." She does not see this same emphasis in writing in other engineering disciplines, and many of her classmates seem to understand the value of writing in engineering contexts and have taken the time to develop the skills they need to be successful.

\section{Current senior project experience}

In the Fall 2017 and Spring 2018 semesters, seniors are enrolled in their capstone project course, where they are working with an industry sponsor to complete a project. The fall semester focused on developing a proposal for a variety of readers, including the project sponsor, and the spring semester was when students run tests and analyze their data to create a report for the sponsor.

Michaela's experience in the capstone course represented a significant improvement over her negative collaborative work experience from the prior semester - and one of the students was involved on both teams. She talked about why she felt the team project was "probably one of the best group projects that I've had as far as team go." She explained: "Everyone has been really committed, which has been really nice, and really excited, like actually enthusiastic about our project." She believed that the success of the project was based on several factors other than student enthusiasm, including the division of roles and each team member's equal contribution to the project and to the writing. She connected the division of writing to the comments Jenn made about approaches for dividing writing in a class presentation.

Sally also indicated that her senior project team was a positive experience. She remarked, "Overall I am really happy with the group that I have. So I'm like not dreading next semester [Spring 2018], which is good." She also commented that in terms of writing, "it's actually been the best team writing experience that I've had because normally [...] it was obvious whose section was whose." For the senior project proposal, Sally felt that the sections were more cohesive and the distinctions were less apparent, which made the writing overall stronger. However, Sally was less satisfied with the written product when compared to her individual writing: "I definitely don't like [the collaborative proposal] as much, because I do like to have a finished product that's really cohesive."

Both students were asked about their perceived impact of the course's attention to project management. Michaela and Sally each expressed that they found the attention to writing to be beneficial as well as helping them understand that the writing was important to success in the course as well as in the profession. The course instructors had been talking about writing in their field in both the junior and senior classes, and the message has been well-received. In fact, Sally mentioned that she has never heard anyone in their program complain about writing, whereas she's heard students in other engineering disciplines do so. 
However, what Michaela commented on about the course approaches highlights the need for attention to project management strategies. While the course did address how to manage the project, such as establishing clear roles within the team, how to divide writing, and how to break up tasks, Michaela found that more attention was needed: "As far as project management, I kind of wish that we had had that discussion not later in the semester, but I wish that it was a recurring discussion. Bring it up again. As the semester goes on, time management gets more and more difficult, and I think bringing it up repeatedly would be helpful." In other words, she found that as deadlines and the end of the semester loomed, they dropped off many of the recommended or even required strategies, such as reviewing each section as a team and building in time for revision and editing.

Where Michaela felt the attention to project management had some impact, Sally pointed instead to past knowledge and knowing who her classmates were. She argued, "I think the biggest factor was that we're seniors, and if we're not doing stuff at a senior level by this point, then we don't deserve to graduate." The knowledge of her peers also was beneficial because they generally understood each other's strengths and weaknesses and could base decisions off of that knowledge. In addition, they could move past politeness conventions and more directly state what they thought or wanted to do. She did note that the focus on editing each other's sections and other project management tips were helpful because it forced her to take time to edit the whole document. She highlighted the issue of time as a primary constraint, which limited her team's ability to make the project as strong as was possible: "So, I think, if we had more time, just in general, like not for this class, but just general time, because everyone has jobs, and everyone has other classes. Then I think we would have had a really, really good project. Because the only reason why we don't spend time on our project is because of time. We want to have the best product possible, and so I think that we definitely would have used those tactics more." Sally also sought Jenn's feedback on sections, which she reported received full credit.

Michaela and Sally are both the one woman on their team, working with three or two men, respectively. Michaela and Sally both took on the role of "communication lead," which meant that they were corresponding (generally over email) with the project sponsor, thus serving as a liaison between the project team and the project sponsor. However, where Michaela had less of a role managing the writing, Sally definitely took the lead with writing and editing. On Michaela's team, one of the men, who was a strong writer, chose to take on more writing, though everyone contributed and she didn't feel like she was asked as a woman to take on more writing. However, she did note, after typical writing/technical gender divisions were pointed out, "It's definitely true, women usually get the writing portion, and men want to do the lab portion it seems like. I never noticed that." On this project, she noted that because one of the men was taking the lead on writing, it was likely because "he kind of forces it to be equally divided." For her, this state "totally is not my typical experience with group projects."

While Michaela's writing was more evenly divided, Sally indicated the split between writing and technical labor was more distinct on her team. One of the men disliked writing and is more experienced with SolidWorks, the program they needed to use for the project, so he took on more 
of that work and less of the writing. So while she believed the overall work was equal, the division between technical and writing was more apparent. In response to a question about equal contributions, Sally responded:

I think not necessarily an equal amount of time contributed, because I think the team leader has done a lot more, because he's actually been designing things on SolidWorks, and neither of us know how to do that at all. So he's just like, "I'm gonna do it all." But I guess his hatred of writing ... He would rather spend more time doing other stuff, than write at all. So I think it balances out in terms of how much people have to do, and how much they like doing it.

Sally later mentioned that the team consciously separated the writing from the technical work, based on strengths and interests.

I would say it's more like, where we separated them. Because the stuff that we were doing, was super technical, and we didn't really even have to write down things to know we're ... We just had to write numbers. So, there's definitely a separation, and then trying to translate that into words was hard.

She commented that because she was doing more of the writing, she was able to talk more fluently and clearly about the technical information as met the needs of the audience, particularly compared to her teammates who had not had that experience.

Thus, both women had positive experiences, some of which could be connected to interventions in the course, and their experiences highlight areas to build on and improve, as will be discussed below.

\section{Course evaluation results}

At the end of the Fall 2017 semester, Harold added several questions to the course evaluation process to assess Jenn's involvement. In the senior-level course, students were asked to respond to the following open-ended questions:

1. Which of the guest speakers and topics do you believe will be most beneficial to you in the future? Please briefly explain why.

2. Please describe the impact having Dr. Mallette teach writing in this course has had on your perspective of writing in engineering.

3. Which aspects of this course were most valuable to your overall learning experience?

In general, students remarked that the attention to writing was beneficial.

- Dr. Mallette's writing assistance was a HUGE help. Writing is difficult but she made it less daunting and was very willing to answer questions.

- Dr. Mallette's [focus on] writing and syntax. We're always told to improve our writing but her specific instructors on grammar and phasing were helpful. 
- Dr. Mallette's writing assistance has improved my writing in this class as well as outside of class. It's also forced me to work towards understanding when to write $100 \%$ technical and when it's alright [sic] to add some non-technical narrative.

- I found it to be helpful, especially that she wanted us to be direct and to not include so many fluffy words. She nailed it, in my opinion.

- I found it very useful and refreshing to have my writing be analyzed the way it was.

- I have learned that I need to improve on being more specific with less words. I also learned that in engineering, you need to give a better background as most of your audience will not be as intimately familiar with your work as you are. I also like the funnel approach that she taught. Overall, I think I got knowledge out of her teaching that will impact my writing for the better.

- It was beneficial. She brought back a focus on quality of the written word vs. just focusing on the quality of the technical content. This will help us present ourselves in a more professional manner in the future.

- The writing and teamwork speakers were helpful and the in-class time given to work on class was nice.

Other students felt that while the writing was valuable, they individually did not need it:

- Although boring, I feel like it was a little helpful. For me, the impact she made really wasn't too big. I already thought I was an okay writer.

- I already know writing is super important, and I think it was helpful for my teammate, but not necessarily for me.

- Minimal. She knew her stuff well, but she was not involved enough to make a difference.

- It was indifferent.

The evaluation comments point to the reality that many students feel able to write successfully as well as the ways Jenn could have been more involved. In general, students seem to recognize the importance of writing and communication and welcome opportunities to develop their skills.

\section{Discussion}

Based on the interviews, the attention to collaboration had some impact on the experiences of at least the two women interviewed and is likely to continue having an impact. Michaela's experience in the senior project is such a stark contrast to her negative experience in the junior year that she seemed particularly sensitive to what the structure provided. In fact, she is currently working with one of the male students who was a member of her previous team, and she noted that "It's been so much better. He's a really talented writer, so it was really unfortunate that he didn't contribute to the last project, because his writing is really ... He's a great writer, so it's been really nice having him actually contribute this semester."

Both women were convinced that ultimately women are stronger writers. On the one hand, if women are stronger writers and are using that skill on team projects, as long as the writing is rewarded, then women shouldn't suffer from taking on a heavier writing load. On the other hand, evidence suggests that women are not being fully recognized for this writing work, particularly if 
the deliverable isn't just a written product $[8,9,10]$. As Sally points out, it would seem that the top male student in her cohort is able to be seen as successful despite not being more than an average writer. While this evidence is anecdotal, it indicates a trend to prioritize other types of skills and knowledge over writing.

In addition, if women are taking on the bulk of the writing, then they are also doing less of other kinds of work - and are likely to lose opportunities to practice other types of skills. In collaborative settings, these women may also face pressure to do more of the writing because a) they want to make sure the writing is strong, b) the prevailing perception is that women are the strongest writers, so the writing should fall to them, or c) other students take up technical tasks as a way to avoid writing. If the writing contributions are visible and rewarded, these tendencies may not be as problematic. In cases where the writing isn't viewed as the primary output for evaluation, however, these labor divisions can mean that women are shouldering the burden of the writing work, and those contributions may not be acknowledged.

Some of these issues might be alleviated by the focus and emphasis on writing in the course. For instance, in the senior project course, writing is given significant space and the course instructors demonstrate that they want students to attend to writing. By frequently bringing in Jenn, a writing expert, having her integrated into the course, and having her provide feedback on writing, students are receiving the message that writing is valued. In addition, the course instructors established roles for each member of the team, and most (if not all) teams had someone whose recognized role was writing/communications lead, thus making those roles more visible. The instructors also heavily weighted the writing portions in terms of evaluation, and they have attempted to institute checks that ensure students are reading other's sections and having conversations about writing. Both Michaela and Sally pointed out how much writing they were asked to do, how much time and energy was spent on writing in the junior and senior project courses, and how they understood that it was essential to their work as engineers.

In addition, Sally's experience in particular highlighted the ways writing can be an advantage to students. She argued that in her case, the writing was visible and allowed her not only to be perceived as a more skilled student but also to talk about the project more easily:

And then the other thing that comes along with writing, I think, I have the advantage in terms of how my professors viewed me, and how my project sponsor views me, because since I'm doing a lot of the writing, I think I will present better. I will probably be the most well-spoken during presentations.

So while the division between writing and technical work means that Sally didn't have the opportunity to develop skills in SolidWorks or other technical elements, she believed that her focus on writing gave her advantages in other areas.

Finally, the attention to writing and communication is visible both in Michaela and Sally's experiences and in the course evaluation comments. Based on these evaluations, while some 
students felt the writing was not that useful for them individually, many students found the focus on writing to be beneficial. What is less clear from the course evaluations, however, is the intersection between writing and collaboration. If the attention to writing was generally beneficial, how did this focus impact student engagement on team projects? Students seemed to indicate that even if they didn't feel like they needed the instruction, it was helpful for their teammates, meaning that it's possible that the attention on writing did improve the process of writing the proposal together. In addition, the background work that the Harold, Janet, and Jenn did to structure the collaboration may not be as visible to the students, and thus was not present in the evaluations. More data will need to be collected to assess the value of the focus on project management, writing, and collaboration on student experiences in the class, particularly for women.

\section{Recommendations for Programs}

While the data may seem to focus on the course structure itself, structural changes affect the environment, which in turn can ensure women's experiences are positive. Through the analysis of the data from the interviews and course evaluations, several themes emerge that lead to specific recommendations for programs to consider to make those structural and environmental changes. While these recommendations are within the framework of what might most benefit women's participation, the recommendations are likely to improve all students' experiences with regard to writing and collaboration. Here, recommendations focus on the following:

- instructors creating clear assignments and communicating expectations,

- structuring collaborative experiences deliberately,

- students having established roles within a project,

- instructors recognizing the ways that student constraints affect the final written products.

\section{Clear/detailed assignments and evaluation}

Research on course design and effective assignments indicate that clear expectations benefit student learning $[16,17,18]$. In engineering courses, to ensure that writing is adequately valued, the assignment and evaluation needs to show precisely what is expected and what will be evaluated. As Sally pointed out about one assignment, the instructor was never clear how the writing factored into the final evaluation; her assumption was that the writing, if adequate, would be less valued than the product itself. In her experience, she believed that because their machine was well designed, the writing itself was less essential. However, if instructors want the writing to be taken seriously as well as be valued, then they need to send that message clearly to students.

In this case, the students recognized that while support for writing was present and the writing itself was emphasized, the instructors shifted the expectations or gave verbal rather than written directions. Michaela mentioned that one element had an upper-limit of three pages, but one of the instructors informed them that they needed more content in that section than was given in the written directions. She also indicated that the dates shifted around, so at times deadlines were unclear and what needed to be submitted wasn't clarified. 
While most of the lack of clarity was because due dates were shifted to accommodate student requests, Michaela's comments on her confusion indicate that students may not be getting the messages the course instructors intend. These complications can create challenges to students trying to accomplish tasks and in understanding what needs to be turned in when and what work should receive primary focus. In this course, the instructors (with feedback from Jenn) are working on revising the assignments to be clearer and to account for what students need. Despite some of the hiccups with miscommunication and shifting deadlines, Michaela did feel that the writing was emphasized throughout the class, and so the students paid attention to it.

In addition, if a written product is part of an assignment, the evaluation methods need to be clearly outlined and the weight of the writing portions should be separated within the assignment itself. Showing how the writing is evaluated as part of an overall project can serve to signal that students should pay attention to writing, or at least that the writing portion will affect their grades. Again, Sally's experience was that her instructor was unclear with how much the writing would impact her team's overall grade. In fact, she expressed that most students in that course were confused or uncertain about how grades would be calculated. Because students are attuned to grading and evaluation, instructors can use evaluation as a way to signal a) that the writing is important and valuable, b) what they will be assessing in the writing, and c) ensure expectations are clearly communicated.

\section{Structure to collaboration}

In addition to providing clear guidelines and evaluation, instructors need to support students in developing teamwork skills. While engineering students likely have had experiences with collaboration in the past, rarely have they had explicit instruction on how to work productively on a team, including creating schedules, dividing tasks, and solving problems that arise [1]. Thus, instead of assuming students know how to work together effectively, instructors should spend some time providing structure to guide the collaboration, even in a senior-level project course.

These steps can ensure that all members understand how to work together, and it can also provide openings to address challenges that women (and/or other underrepresented students, such as multilingual students or minority students) might face in collaborative settings. For instance, in discussing potential team conflict, instructors could raise awareness of problems that might emerge from differences, including how men and women are often socialized to communicate. Women in particular are likely to be accused of not providing clear leadership or direction when they are in leadership positions, a charge that might be somewhat unfair, and one that might emerge from perceptions of their communication styles [5]. Resources that help raise these issues exist, and a text such as Wolfe's Team Writing: A Guide to Working in Groups may provide a resource to use to structure collaboration, have conversations about team diversity, and explore strategies to resolve team conflicts [19].

As part of the structuring, instructors should also provide opportunities for students to communicate problems early, such as through meeting minutes and project updates. In addition, 
students should be asked to evaluate their peers at the end of a project, or even periodically. Michaela talked about the ways that the instructors modified assignments and approaches after her disastrous group experience, including being flexible with her submission and adding in a peer evaluation process. She indicated that the peer evaluation was added because of her negative experience, and the process offers the chance for students to ensure their experiences are visible. While conflict on projects may not be completely avoidable, providing structure can give students a chance to develop skills for how to handle these situations, how to communicate with one another, and how to address problems as they arise instead of when they get out of hand.

\section{Establishing Roles}

As part of providing structure for collaboration, instructors can also establish roles for teams, requiring a project manager as well as other roles appropriate to the nature of the project. These roles could be assigned by the instructor or selected by the students. While Michaela's experience reveals the challenges that could emerge when team roles are assigned, assigning roles might also give the opportunity to develop leadership skills to students who might not otherwise be given the chance.

In the cases where an instructor might wish to assign roles, roles should be assigned to all members, and the person selected to lead should be willing and capable of taking on leadership work. If instructors choose to assign roles, they should also provide guidance and support to the students given leadership roles, particularly if they have not yet had the opportunity to develop those skills. For instance, Michaela indicated that she did not want to be the leader, and that some of the issues may have emerged because the others on her team were not interested in being involved if they couldn't lead. However, she mentioned some of the ways that she attempted to get the other members to contribute, which may have been perceived as more passive rather than directive, making them more likely to ignore her. In this case, Michaela may have benefited from strategies to communicate clear expectations and to ensure that each member understood what was needed, particularly highlighting gender performance expectations that might have influenced the interactions.

In Michaela's case, the other issue was that the only role assigned was that of leader; no other roles were provided. If instructors recognize that roles are needed to ensure projects succeed, they should also be prepared to support student leadership development as well as outlining the functions and responsibilities of various positions. This support is particularly beneficial for women such as Michaela, who identifies as soft-spoken and not particularly assertive as a leader. Her experience as lead on the project might have been more positive if she had been supported and given resources to know how to approach the situations she found herself in. In addition, her teammates would have benefited from having assigned roles as well as understanding the instructor's goal in designating roles. Furthermore, if instructors provide support for leadership and communication, all students would benefit: women would learn strategies to be heard and learn, and research suggests the men would also perform better and be more open to learning from others in a collaborative setting [5]. A larger conversation could also be had about ideas 
and stereotypes about leadership, including a discussion about gender and communication norms. These lessons would hopefully benefit students when they move into workplace settings, enabling them to understand diverse working styles and respect a range of communication techniques.

Most frequently, though, students are encouraged to select their own roles or to position themselves in roles that best suit their interests and abilities. If students are asked to select their own project manager or team leader and designate other roles, then instructors also should point out tendencies about who is seen as "naturally" being better at certain roles. For instance, a conversation about the ways that women are expected to take up note-taking or secretarial/administrative labor would be needed to prevent the assumption that the one woman on a team (a real possibility in a male-dominated engineering course) will do work associated with note-taking or writing. In addition, the leadership role perhaps should not automatically go to the person who has always been the leader. If someone wishes to develop leadership skills or gain experience in project administration, then offering resources and support would also be ideal to encourage that person to take up that role.

\section{Recognition of student constraints}

The final recommendation is to recognize how students make strategic choices about their roles and participation based primarily on constraints on their time and skills. Ideally, students would choose to take on new roles and use opportunities to learn. The reality is, however, that students make choices that play to their strengths and avoid their weaknesses. These choices are due to the challenges of projects in other courses, constraints on time, and the desire to produce the best work possible.

Sally in particular highlighted issues with time constraints. She pointed out that often class sessions didn't seem the most useful, and the best use of the class periods would have been allowing them to work on their projects because it was a struggle to find time to meet outside of class. This lack of time meant that students prioritized different tasks or did not take time to read each other's work, or they were unable to focus on the writing in the midst of other concerns. And the team members certainly did not take on tasks that they were weaker in or would take them more time. As Sally commented, "Because a lot of times, the best writer will be the writer." While Michaela's group divided up the writing more evenly, Sally took on the most writing, partly because they all wanted to get a good grade. Sally pointed out that one group member "is from Saudi Arabia, so he is not a native English speaker. So I'm sure he would like to know how to write better." But in the time constraints of the semester and the desire to earn the highest grade possible, little space exists for a student to necessarily strengthen those skills - thus, the best writer continues to produce the most writing.

Sally's comments about how writing roles were determined underscores the challenge here. While ideally all students will practice both technical and writing skills, it's more likely that groups will divide labor along lines of who is best able to perform each task. As research has shown, this division could disadvantage women as they are asked to take up more writing at the 
cost of developing technical skills [9]. In addition, the assumption is that women are better at writing; both Michaela and Sally expressed that belief, which means that writing is more likely to fall to women. Group members may not make these choices with gender in mind, though gender may influence who ends up doing what.

In some ways, this division of labor is unavoidable: given the constraints on time and the desire to perform adequately on a project, each team member will likely attempt to contribute in the way they feel best. As Michaela commented, "Professors are always like, 'You have to split [the writing] evenly,' but they can't babysit you. Nobody ever splits it perfectly." Thus, to account for these constraints, instructors should employ strategies to give students space and time to develop new skills. For instance, an assignment can ask students to pick one area that they see as a gap in their skills and work on that area with support. In addition, Michaela suggested that having each member within a group produce an individual update would make it harder for someone to avoid writing or hide their skill level in a collaboratively-written, edited report or document. Similarly, Sally suggested a weekly update from each team member as both a way to alert the instructor about what's going on within the project as well as an opportunity for each student to individually think about writing, since they would be asked to explain in a written memo what they did or accomplished the preceding week. These updates could evaluated in a less time-consuming way than the formal reports, but they could also provide a space for individuals to reflect on their learning, an instructional technique that has benefits for writing development.

In addition to providing opportunities to work toward new skills, instructors can recognize the work that may be rendered invisible in a final product. In the case of the project building a deliverable, it may be that the writing was somewhat invisible; if students created a stellar product but a weak report, they may still earn a strong grade, while a mediocre product with excellent writing may not be recognized for its strengths. Instructors should find ways to make the writing work more visible in ways that may highlight the writer's contributions, which would make the work often performed by women more obvious and thus rewarded.

\section{Conclusion}

This research represents only a small snapshot of women's experiences writing in collaborative engineering settings. Future research of the English-MSE partnership will examine a larger sampling of women to gather more experiences to examine and analyze. In addition, the recommendations proposed here could be applied in multiple engineering disciplines and studied to determine if these interventions are effective at enhancing women's experiences with group work.

Writing itself represents just one aspect of collaborative projects, and other factors also could be examined to assess the impacts on women. For instance, perceptions of writing intertwine with interpersonal communication approaches; gender often influences how writers and speakers are viewed by others on a team. Research has demonstrated that gender influences perceptions of criticism, and women's writing may be more likely to be read differently based on beliefs about 
the writer's gender identity $[5,9,12]$. Future work should continue exploring how writing and gender identity interact as well as developing strategies to raise awareness of those interactions. Additional interventions are possible in the university setting to work toward that awareness, such as creating a gender and communication toolkit that could be part of professionalization workshops both within and outside of engineering courses.

As the engineering field continues to examine factors that increase women's participation in engineering settings, the combination of writing, collaboration, and gender offers an area for exploration and sites for intervention. As research has demonstrated, collaborative writing presents significant challenges for students as they learn to write in engineering [1]. Furthermore, these project may disadvantage women, making them feel unwelcome in engineering [5]. Focusing on women's experiences and what they need in order to feel successful will not only benefit the retention of women, but also improve collaboration and learning for most students in a course. 


\section{References}

[1] M. Poe, N. Learner, and J. Craig. Learning to Communicate in Science and Engineering: Case Studies from MIT. Cambridge: The MIT Press, 2010.

[2] J.L. Huff, C.B. Zoltowski, and W.C. Oakes, "Preparing engineers for the workplace through service learning: Perceptions of EPICS alumni," Journal of Engineering Education, vol. 105, no. 1, pp. 43-69, Jan. 2016.

[3] Y. Liu, "Renovation of a mechanical engineering senior design class to an industry-tied and team-oriented course," European Journal of Engineering Education, vol. 42, no. 6, pp. 800-811, 2017.

[4] J.A. Leydens, "Novice and insider perspectives on academic and workplace writing: Toward a continuum of rhetorical awareness," IEEE Transactions on Professional Communication, vol. 51, no. 3, pp. 242-263, Sept. 2008.

[5] J. Wolfe and E. Powell, "Biases in interpersonal communication: How engineering students perceive gender typical speech acts in teamwork," Journal of Engineering Education, 98, pp. 516, Jan. 2009.

[6] D.Z. Gunspan, S.L Eddy, S.E. Brownell, B.L. Wiggins, A.J. Crowe, and S.M. Goodreau, "Males under-estimate academic performance of their female peers in undergraduate biology classrooms," PLoS ONE, vol. 11, no. 3, Feb. 2016. [Online]. Available https://doi.org/10.1371/journal.pone.0148405. [Accessed Feb. 5, 2018].

[7] J. Wolfe and K.P. Alexander, "The computer expert in mixed-gendered collaborative writing groups," Journal of Business and Technical Communication, vol. 19, no. 2, pp. 135-170, April 2005.

[8] J.C. Mallette, "Writing and women's retention in engineering," Journal of Business and Technical Communication, vol. 3, no. 4, pp. 417-422, Oct. 2017.

[9] J.C. Mallette, "Expanding efficiency: Women's communication in engineering," Engineering Studies, vol. 9, no. 3, pp. 195-221, Dec. 2017.

[10] P. Voosen, "The subtle ways gender gaps persist in science," Chronicle of Higher Education, Mar 6, 2016. [Online]. Available http://chronicle.com/article/The-Sublte-WaysGender-Gaps/235598. [Accessed Feb. 5, 2018].

[11] D. Charney, J.H. Newman, and M. Palmquist. “I'm just no good at writing': Epistemological style and attitudes toward writing," Written Communication, vol. 12, no. 3, pp. 298-329, 1995. 
[12] J.T. Haswell and R.H. Haswell, "Gendership and the miswriting of students," College Composition and Communication, vol. 46, no. 2, pp. 223-54, 1995.

[13] R.H. Haswell and J.T. Haswell, "Gender bias and critique of student writing," Assessing Writing, vol. 3, no. 1, pp. 31-83, 1996.

[14] D.W. Knight, L.E. Carlson, and J.F. Sullivan, "Improving engineering student retention through hands-on, team based, first-year design projects." 31st International Conference on Research in Engineering Education, June 22-24, 2007, Honolulu, HI.

[15] R.K. Yin, Applications of Case Study Research. Thousand Oaks, CA: Sage, 2012.

[16] L.D. Fink, A Self-Directed Guide to Designing Coruses for Specific Learning. n.d. [E-book]. Available: http://finkconsulting.info/major-publications/. [Accessed February 5, 2018].

[17] W. Walvoord and V.J. Anderson, Effective Grading: A Tool for Learning and Assessment. San Francisco: Jossey-Bass, 1998.

[18] G. Wiggins, Educative Assessment: Designing Assessments to Inform and Improve Student Performance. San Francisco: Jossey Bass, 1998.

[19] J. Wolfe. Team Writing: A Guide for Working in Groups. Boston: Bedford/St. Martin's, 2010. 


\section{Appendix A: Pre-Project Interview Questions}

1. For the last two semesters, what collaborative projects have you participated in? This can be in engineering courses, other courses, or outside of school, such as student groups, a job, or an internship.

2. For each of those projects, what has been your role?

3. For each project, in what ways was writing a part of the project?

4. For each of your projects, what was your role with regards to writing?

5. In comparison with the other members on the project, did you contribute more or less or about the same? How was the writing work divided? How did your team approach the writing?

6. If you wrote more, did you do less of the technical work? If you wrote less, did you do more of the technical work? In other words, how did the overall workload balance out?

7. What influence do you think your gender might have on how the work was divided?

8. What influence do you think your gender might have on your views about writing or your experience writing?

9. In what ways do you view writing as a skill? 


\section{Appendix B: Post-Project Interview Questions}

1. Describe your team experience with this project. How do you feel it went overall?

2. Describe the ways your team divided the writing tasks. How do you feel the writing turned out overall?

3. Compare this writing experience with a past experience. In what ways was it similar? Different?

4. The course spent a lot of time talking about writing and project management. What impact do you think these discussions and approaches (such as asking all team members to review the document and incorporating the writing work into the task schedule) had on your experience as a writer?

5. In what ways did your team pay attention to the writing as a part of the success of the project? 6. Often, writing can be divided along gender lines, with women taking up more of that writing work. What was your experience in relation to that division?

7. In the previous interview, we asked you about how you viewed writing as a skill. In what ways has your perspective changed? 